\title{
Tratamiento del acné en la adolescencia
}

\author{
Treatment of acne in adolescents
}

Nicole Crimer*, Roberto Mercau*, David Cólica*

\begin{abstract}
Resumen
El acné es la enfermedad dermatológica más común de la adolescencia. Aunque casi todos los casos remiten alrededor de la tercera década de la vida, cuando este problema conlleva una carga emocional para el paciente se requiere indicar tratamiento. En esta actualización, los autores revisan los distintos grados de compromiso de esta patología, el tratamiento y los niveles de evidencia que tiene cada uno de ellos, con el objetivo de facilitar a los médicos de atención primaria el manejo de los pacientes que presentan esta enfermedad.
\end{abstract}

\begin{abstract}
Acne is the most common dermatological condition in adolescents. Even though almost all cases will resolve around the third decade of life, treatment is indicated when this health problem carries an emotional burden for the patient. In this update, the authors review the grades of involvement of the disease and the available treatments according to levels of evidence, with the aim of helping primary care physicians to manage the patients presenting this illness.
\end{abstract}

Palabras clave: acné vulgar, adolescente, tratamiento farmacológico. Key words: acne vulgaris, adolescent, drug therapy.

Crimer N, Mercau Cossio R, Cólica D. Tratamiento del acné en la adolescencia. Evid Actual Pract Ambul. 2018;21(3):89-91.

\section{Introducción}

El acné es la enfermedad dermatológica más común en adolescentes. Conlleva una elevada carga psicológica acompañada de vergüenza y ansiedad, con un gran impacto en la vida social. Las cicatrices pueden ser desfigurantes y de por vida. Si bien en la mayoría de los casos es una patología benigna y que tiende a autolimitarse, el tratamiento se orienta a disminuir la carga psicosocial y a mejorar la autoestima.

La prevalencia entre adolescentes es del 35 al 90\%, a predominio del sexo masculino. Tiende a resolver en la tercera década, pero puede persistir inclusive en la adultez.

El mecanismo subyacente en su patogénesis es la inflamación del folículo sebáceo, en la que se involucran varios factores: la hiperqueratinización folicular, el aumento de la producción del sebo, y la colonización por el Propinobacterium acnes.

Las glándulas sebáceas se hiperplasian con la estimulación de la producción del sebo mediada por el metabolito activo de la testosterona (la dehidroepiandrosterona o DHEA) durante la adrenarca. Este problema de salud suele remitir en la mayoría de los casos alrededor de la tercer década de la vida, asociado con el descenso hormonal.

El micromedo es el precursor de las lesiones clínicas del acné vulgar, que incluyen: comedones abiertos, comedones cerrados, pápulas, pústulas, nódulos, quistes, abscesos y cicatrices.

Los diagnósticos diferenciales se enumeran en el cuadro 1.

Cuadro 1. Diagnósticos diferenciales del acné vulgar

- Foliculitis bacteriana: erupción de inicio brusca, se extiende en zonas de rascado o afeitado.

- Acné por drogas: investigar el uso de andrógenos, hormona adrenocorticotropa, bromuros, corticosteroides, anticonceptivos orales, yoduros, isoniazida, litio y fenitoína.

- Miliaria: sarpullido por exposición al calor o esfuerzo físico.

- Dermatitis seborreica: escamas grasientas y máculas amarillas. - Rosácea: eritema y telangiectasias. Sin comedones.

\section{Mitos y verdades}

1- "Los jabones astringentes están indicados para curar el acné". Los jabones, detergentes y astringentes remueven el sebo de la piel, pero no alteran la producción del mismo, y no resuelven el origen del problema. Por el contrario, el trauma mecánico generado por el roce promueve la liberación de mediadores inflamatorios, que de manera directa aumentan el acné. Por este motivo, es recomendable que a las personas con acné se les indique secar la piel con unos finos toques de toalla.

2- "A un paciente con acné hay que indicarle que evite comer chocolates". No hay evidencia que una dieta baja en grasas prevenga o disminuya el acné. La prohibición del chocolate u otros alimentos como por ej. la mayonesa, no tiene sustento científico. Sin embargo, un meta-análisis de estudios observacionales mostró que la ingesta de lácteos (leche, queso, yogur) podría exacerbar el acné.

3- "Hijo de padres con acné tiene más probabilidades de tener acné". Los pacientes con familiares directos con acné, tienen riesgo aumentado de presentar la patología.

4- "No te estreses que te vas a brotar". No se pudo demostrar la asociación entre el acné y el estrés.

\section{Tratamiento}

Es importante considerar que, en la mayoría de los casos, el tratamiento del acné se indica sólo si afecta al paciente, ya que como fue mencionado, esta patología es benigna y resuelve sola alrededor de la tercer década de vida. El grado de acné más severo, también denominado acné conglobata, es una de las excepciones; en este caso se debe indicar el tratamiento para prevenir la cicatrices.

De acuerdo a la severidad de las lesiones, existen diferentes opciones de tratamiento farmacológico (ver tabla 1 y figuras 1 a 4). A continuación se describen en más detalle algunos aspectos prácticos a tener en cuenta en las distintas opciones terapeúticas y los niveles de evidencia que los avalan (ver cuadro 2).

\section{Cuadro 2.. Niveles de evidencia}

Nivel A: Pruebas consistentes y de buena calidad orientadas al paciente.

Nivel B: Evidencia orientada al paciente inconsistente o limitada. Nivel C: Consenso u opinión de expertos, evidencia orientada a la enfermedad, práctica usual o series de casos.

Queratolíticos tópicos: retinoides

Constituyen ejemplos de este grupo el adapalene, el tazaroteno, la tretinoína.

Su uso en tratamiento del acné inflamatorio y no inflamatorio cuenta con nivel de evidencia A.

Su uso como terapéutica de mantenimiento, luego del tratamien-

* Servicio de Medicina Familiar y Comunitaria, Hospital Italiano de Buenos Aires. nicole.crimer@ hospitalitaliano.org.ar 
to con antibióticos orales está avalado por nivel de evidencia C. Se recomienda aplicar una fina capa luego de asear y secar la zona afectada.

La tretinoína se presenta en concentraciones al 0,025\%, 0,05\%, $0,1 \%$ y $0,2 \%$, en crema o gel por 10,20 y $30 \mathrm{ml}$. El adapalene se presenta al $0,1 \%$ en forma de crema o gel.

Se indican 1 o 2 aplicaciones diarias. Puede ser adecuado empezar con las cremas de menor concentración para mejorar la tolerancia. Al principio puede aparecer exfoliación cutánea transitoria, en cuyo caso el tratamiento puede suspenderse temporalmente o disminuir la frecuencia de aplicación hasta que desaparezca.

El efecto beneficioso puede tardar en aparecer entre 6 y 8 semanas.

A su vez, se pueden utilizar para el tratamiento de mantenimiento, luego de haber alcanzado el objetivo terapéutico con los medicamentos que se prescriben por vía sistémica. El adapalene es el mejor tolerado aunque hay evidencia que sugiere que el tazaroteno es más efectivo.

Los eventos adversos más frecuentes incluyen: prurito, sequedad y eritema.

Antibióticos tópicos: peróxido de benzoilo, eritromicina, clindamicina

Su uso combinado para reducir el riesgo de resistencia bacteriana cuenta con nivel de evidencia $\mathrm{C}$.

El uso de antibióticos tópicos en conjunto con retinoides tópicos tiene un nivel de evidencia $A$.

El peróxido de benzoilo se encuentra en concentraciones al $2,5 \%$ o al $5 \%$. La clindamicina, al $1 \%$ o al $2 \%$, y la eritromicina, al $1,5 \%$ y al $2 \%$.

La forma de uso es similar a los queratolíticos tópicos. Existen formulaciones que suman ambas presentaciones, como p.ej. peróxido de benzoilo con eritromicina, con clindamicina o retinoides tópicos. Las combinaciones son más efectivas que el uso de cada agente en forma aislada.

\section{Tratamiento antibiótico sistémico}

Su uso en tratamiento de acné moderado y severo cuenta con nivel de evidencia A.

Se aconsejada una duración del tratamiento entre 6 y 12 semanas.

Se pueden emplear tetraciclinas (tetraciclina, $250 \mathrm{mg}$ cada 12 horas; minociclina, $50 \mathrm{mg}$ cada 12 horas; o doxiciclina, $100 \mathrm{mg}$ por día) o macrólidos (eritromicina $500 \mathrm{mg}$ cada 12 horas). La eritromicina tiene la ventaja de poder utilizarse durante el embarazo y la lactancia. La azitromicina es un macrólido alternativo que tiene la ventaja de poder emplearse en dosis de $500 \mathrm{mg}$

Tabla 1. Tratamiento del acné según la severidad de la afección. diarios durante tres días consecutivos, repitiendo a los 10 días. Las tetracicilinas tienen la desventaja de constituir drogas que se metabolizan por vía hepática e interactúan con muchísimos fármacos. Tienen por lo general, mala tolerancia gastrointestinal. Dado que suele aparecer resistencia antimicrobiana, se recomienda su utilización en simultáneo con el peróxido de benzoílo. La tetraciclina es el fármaco de este grupo que genera menor resistencia. Entre los eventos adversos se encuentran el pseudotumor cerebral y la pigmentación azul pizarra.

Los eventos adversos más frecuentes de los macrólidos son las molestias gastrointestinales.

Anticonceptivos hormonales

Si bien se entiende que cualquier anticonceptivo hormonal reduce la producción de sebo y disminuye la transformación periférica de los andrógenos, ciertos anticonceptivos hormonales fueron aprobados por la FDA específcamente para su uso en acné: el acetato de noretisterona $1 \mathrm{mg}$ + etinilestradiol $0,02 \mathrm{mg}$ (no disponible en estas dosis en Argentina), norgestimato 0,180 $\mathrm{mg}+$ etinilestradiol $0,035 \mathrm{mg}$, y drospirenona $3 \mathrm{mg}+$ etinilestradiol 0,02 mg.

Independientemente de su acción sobre el acné (nivel de evidencia A), dado que muchos medicamentos que se usan en el tratamiento de este problema tienen riesgos teratogénicos, es de buena práctica indagar sobre el uso de métodos anticonceptivos e indicar anticonceptivos hormonales de ser necesario.

\section{Isotretinoína oral}

Se emplea en dosis de 0,5 a $1 \mathrm{mg} / \mathrm{kg} /$ día durante 6 a 8 meses, hasta llegar a una dosis acumulada de 120 a $150 \mathrm{mg} / \mathrm{kg}$ de peso. Este fármaco tiene como eventos adversos: sequedad de mucosas, hipertrigliceridemia, teratogenicidad y hepatotoxicidad, por lo que es necesario realizar un laboratorio basal de la función hepática y del perfil lipídico, y controles cada 3 meses.

En el cuadro 3 se señalan los cuidados generales.

Cuadro 3. Recomendaciones generales para el tratamiento del acné.

- Mantener la cara limpia, lavar con jabón normal, secar con suaves golpes de toalla y evitar frotar la piel.

- Evitar cosméticos, perfumes y maquillajes.

- Durante el tratamiento médico, hacer énfasis en la protección del sol y en las mujeres en el uso de anticonceptivos, ya que la mayoría de los productos son queratolíticos y teratogénicos.

Fuente: Ebell M A y col. Am Fam Physician 2004; 69.549-57

\begin{tabular}{|c|c|c|c|}
\hline \multicolumn{2}{|l|}{ Tipo de acné } & Lesiones predominantes & Tratamiento más adecuado \\
\hline \multicolumn{2}{|l|}{ Grado I - Acné comedoniano } & comedones - algunas pápulas & Queratolíticos tópicos \\
\hline \multirow[t]{2}{*}{ Grado II - Acné papulopustuloso } & Moderado & comedones - pápulas - pústulas & $\begin{array}{l}\text { Queratolíticos tópicos } \\
\text { Antibióticos tópicos durante } 3 \text { meses } \\
\text { (antibioticoterapia oral si no hay mejoría) } \\
\text { Anticonceptivos orales en mujeres }\end{array}$ \\
\hline & Grave & comedones - pápulas - pústulas - quistes - nódulos & $\begin{array}{l}\text { Queratolíticos tópicos } \\
\text { Antibióticos por vía oral durante } 3 \text { a } 6 \text { meses } \\
\text { Anticonceptivos orales en mujeres } \\
\text { Si no hay mejoría: isotretinoína oral }\end{array}$ \\
\hline \multicolumn{2}{|l|}{ Grado III - Acné conglobata } & abscesos - cicatrices atróficas y queloideas & Anticonceptivos orales en mujeres - Isotretinoína oral \\
\hline
\end{tabular}




\section{Figura 1. Acné grado I.}

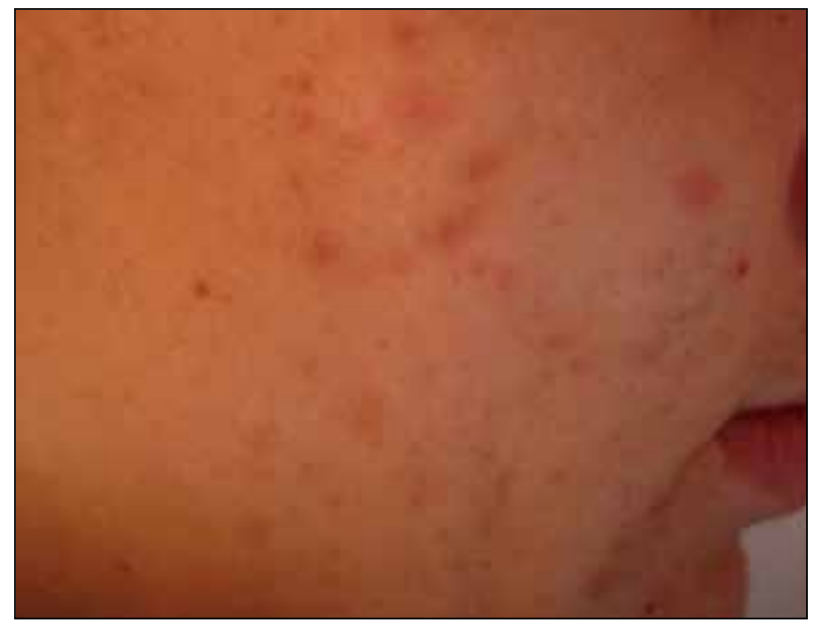

Figura 2. Acné grado II moderado.

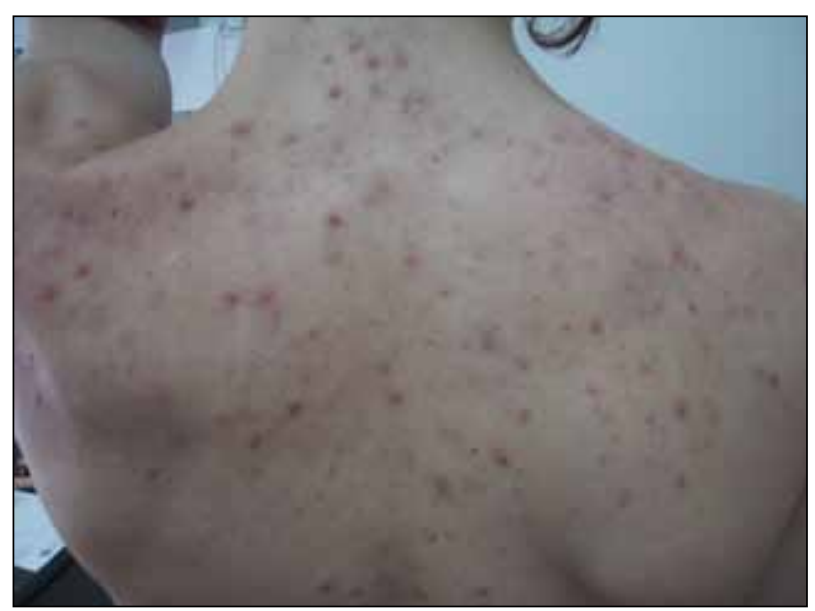

Figura 3. Acné grado Il severo.

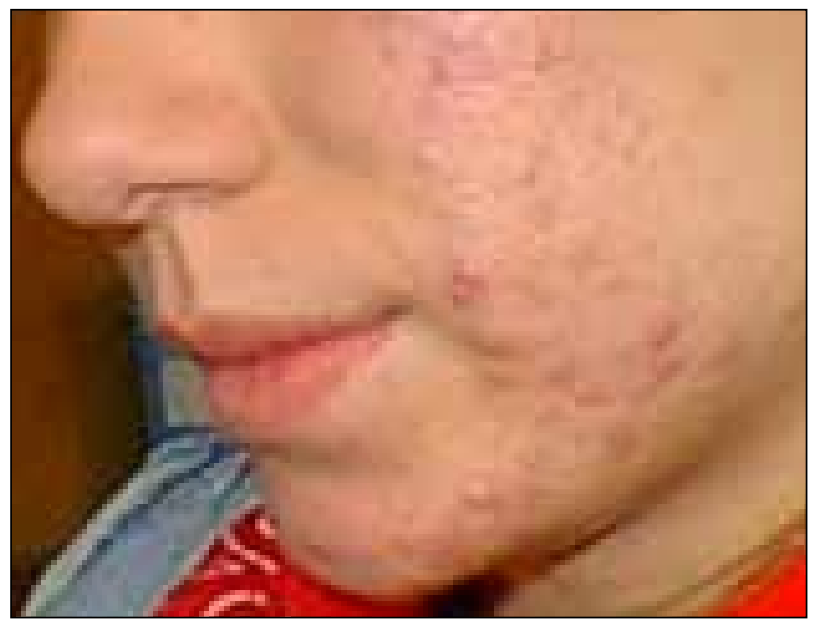

Figura 4. Acné grado III.

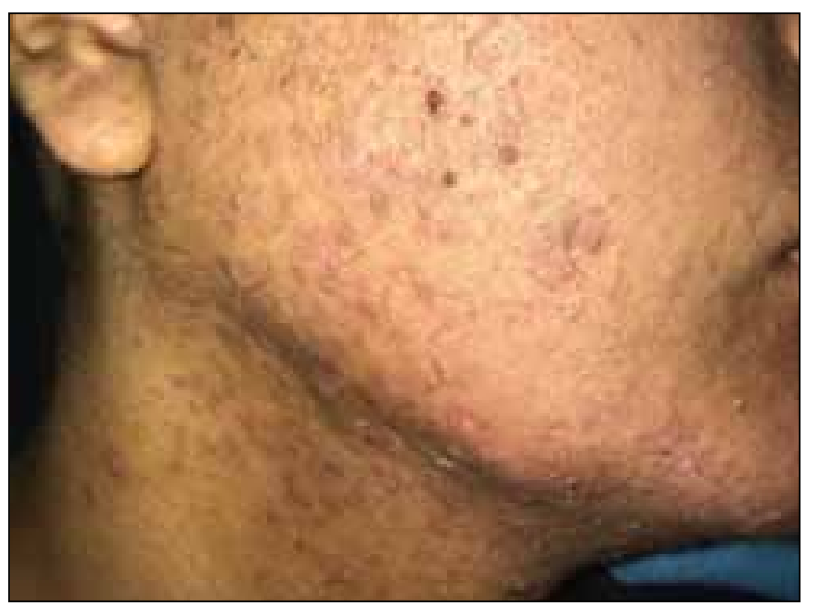

\section{Agradecimientos}

A las Dras. Belén Fette y Noelia Capellato, del Servicio de Dermatología, Hospital Italiano de Buenos Aires, por la imágenes de pacientes con lesiones de distintos grados de severidad.

\section{Bibliografía}

- Servicio de medicina familiar y comunitaria del hospital italiano. Acné Vulgar. In: Carrete, P, Barani, M (eds.) Medicina Familiar y Práctica Ambulatoria. Ciudad Autónoma de Buenos Aires: Médica Panamericana; 2016. p. 1962-1968

Titud, S, y col. Diagnosis and treatment of acne. Am Fam Physician. 2012;86(8):734-740

- Simonart, T. Newer Approaches to the Treatment of Acne Vulgaris. Am J Clin Dermatol. 2012;13(6): 357-364.

- Purriños Orgeira, L. Guia clinica de acné. Fisterra. [Online]. Disponible en: https://www.fisterra.com/guias-clinicas/acne/ [Consultado el 22 de Marzo de 2018] 